\title{
06;07
}

\section{Локальное анодное окисление слоев графена на SiC}

\author{
(C) П.А. Алексеев ${ }^{1}$, Б.Р. Бородин ${ }^{1}$, М.С. Дунаевский ${ }^{1}$, \\ А.Н. Смирнов ${ }^{2}$, В.Ю. Давыдов ${ }^{1}$, С.П. Лебедев ${ }^{1}$, А.А. Лебедев ${ }^{1}$ \\ ${ }^{1}$ Физико-технический институт им. А.Ф. Иоффе РАН, Санкт-Петербург, \\ Россия \\ ${ }^{2}$ Санкт-Петербургский национальный исследовательский университет \\ информационных технологий, механики и оптики, Санкт-Петербург, \\ Россия \\ E-mail: npoxep@gmail.com
}

Поступило в Редакцию 15 января 2018 г.

Методом локального анодного окисления получены области оксида графена на $\mathrm{SiC}$. Изменение свойств поверхности подтверждено методами атомносиловой микроскопии и комбинационного рассеяния света. Получены экспериментальные данные о проводимости, потенциале и топографии окисленных областей. Показано, что окисление приводит к повышению поверхностного потенциала. Установлена связь между такими параметрами окисления, как скорость сканирования и напряжение на зонде. Методом локального анодного окисления выполнена литография графеновой наноленты (nanoribbon) шириной $\sim 20 \mathrm{~nm}$, а также получено наносужение (nanoconstriction) шириной $\sim 10 \mathrm{~nm}$.

DOI: 10.21883/PJTF.2018.09.46063.17211

Графен - слой углерода, атомы которого образуют гексагональную двумерную кристаллическую решетку [1]. Графен является перспективным материалом для создания электронных и оптоэлектронных устройств нового поколения. Уже сейчас он применяется для создания тонкопленочных транзисторов [2], OLED-дисплеев [3] и многих других устройств. Экономически выгодными для многочисленных приложений являются болышеразмерные пластины высококачественного однородного графена. Наиболее распространенный подход, используемый для получения графена большой площади, - химическое осаждение из паровой фазы на тонкую металлическую фольгу с последующим его переносом на диэлектрическую подложку. Однако ориентация доменов в выращенном таким способом графене является случайной, 
что снижает его транспортные характеристики. Высококачественный эпитаксиальный графен с регулярной ориентацией доменов может быть выращен методом термодеструкции полуизолирующей монокристаллической подложки карбида кремния ( $\mathrm{SiC})[4,5]$. Большим преимуществом такой технологии является отсутствие необходимости переноса выращенной пленки на подложку диэлектрика.

Для создания приборов на основе графена, как правило, используется фото- или электронная литография. Большинство литографических методик подразумевает нанесение и удаление резиста с поверхности графена. Однако электронная структура графена крайне чувствительна к структурным дефектам и поверхностным адсорбатам, которые снижают подвижность носителей заряда [6]. Альтернативным методом литографии, исключающим использование резиста, является локальное анодное окисление (ЛАО) [7,8]. В данном методе под зондом атомно-силового микроскопа при приложении электрического напряжения происходит диссоциация поверхностной водной пленки с последующим окислением слоя графена. Окисление происходит только в области формирования водного мениска при контакте зонда с поверхностью, и электронная структура графена на остальных участках поверхности не нарушается. Возможность локального анодного окисления графена на $\mathrm{SiC}$ была показана в работе [8]. Следует отметить, что электронные свойства оксида графена (GO) на $\mathrm{SiC}$ остаются практически неизученными. Кроме того, в большинстве подобных работ с ЛАО авторы используют малые электрические напряжения и, как следствие, малые скорости зонда, что затрудняет литографию на образцах большой площади. Установка, применяемая в настоящей работе, позволяет прикладывать напряжения до $-50 \mathrm{~V}$, поэтому открывается возможность исследования различных режимов окисления при варьировании напряжения и скорости зонда. Целью работы является исследование методами атомно-силовой микроскопии (АСМ), кельвин-зонд-микроскопии, комбинационного рассеяния света (КРС) режимов окисления графена, электронных и структурных свойств пленок GO.

Эксперимент проводился на микроскопе Ntegra Aura (NT-MDT) с использованием DCP (NT-MDT) проводящих зондов с диаметром острия $100 \mathrm{~nm}$. Образец представлял собой монослойный графен высокого качества с небольшой долей $(\sim 10 \%)$ включений двухслойных островков с субмикронными размерами, полученный методом термоде-

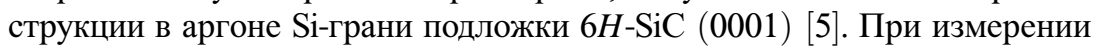

3* Письма в ЖТФ, 2018, том 44, вып. 9 


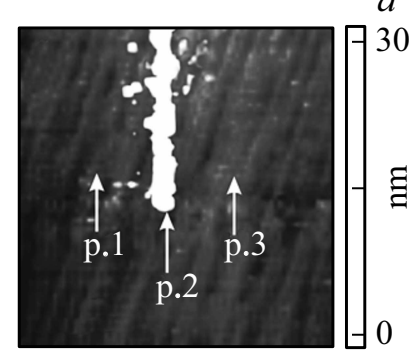

$5 \mu \mathrm{m}$ $a$
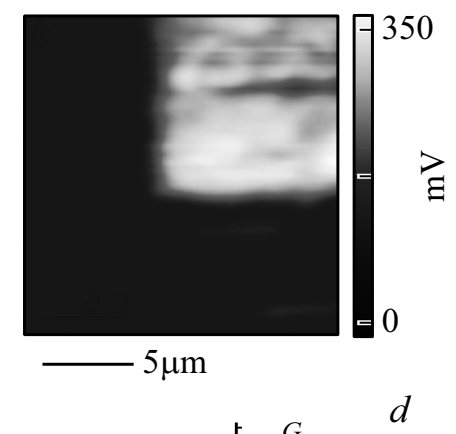
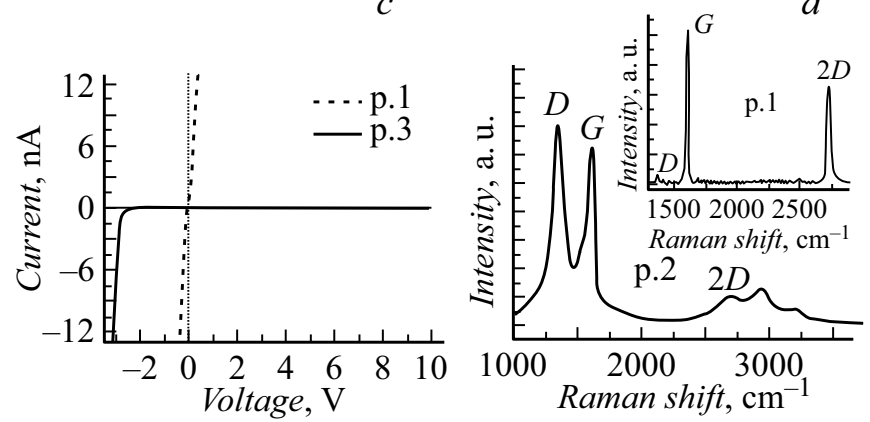

Рис. 1. Топография $(a)$, распределение поверхностного потенциала $(b)$ после воздействия, вольт-амперные характеристики, измеренные в точках р. 1 и p. 3 $(c)$, и спектр КРС, полученный в точке р. $2(d)$. На вставке показан спектр, полученный в точке р. 1.

вольт-амперных характеристик (BAX), а также при ЛАО электрическое напряжение прикладывалось между АСМ-зондом (первый электрод) и прижимным контактом к поверхности образца (второй электрод). Уровень влажности контролировался с помощью встроенной в микроскоп системы. Измерения спектров КРС проводились при комнатной температуре в геометрии „обратного рассеяния“ на спектрометрической установке Horiba Jobin Yvon T64000, оснащенной конфокальным микроскопом, что позволяло получать информацию из области графеновой пленки диаметром $\sim 1 \mu \mathrm{m}$. Для возбуждения спектров КРС использовался $\mathrm{Nd}$ : YAG-лазер $(\lambda=532 \mathrm{~nm})$.

Письма в ЖТФ, 2018, том 44, вып. 9 
На рис. 1 представлено АСМ-изображение топографии $(a)$ и карта распределения поверхностного потенциала $(b)$ участка поверхности с окисленной областью в правом верхнем квадранте (р. 3). Окисление проводилось при напряжении $-30 \mathrm{~V}$ и скорости зонда $1.5 \mu \mathrm{m} / \mathrm{s}$ в контактном режиме с силой нажима $60 \mathrm{nN}$ при относительной влажности $45 \%$. При окислении быстрая ось сканирования была горизонтальной, поэтому на границе области окисления на рис. 1, $a$ образовалась вертикальная полоса (p. 2). Возникновение данной полосы обусловлено частичным переносом оксида графена на край области, в которой производилось окисление. На карте распределения поверхностного потенциала видно, что область, подвергшаяся воздействию, имеет четкие границы и ее потенциал на $350 \mathrm{mV}$ выше, чем потенциал невозмущенных областей. Известно, что поверхностный потенциал $\mathrm{SiC}$ без слоя графена также на $350 \mathrm{mV}$ выше, чем потенциал $\mathrm{SiC}$ с монослоем графена. Таким образом, окисление графена приводит к снижению экранировки потенциала $\mathrm{SiC}$ под ним.

На рис. 1,c представлены ВАХ, измеренные при контакте зонда с невозмущенной и окисленной поверхностью в точках р. 1 и p. 3 соответственно. ВАХ, полученная при контакте зонда с графеном (p. 1), имеет линейный вид, характерный для омического контакта с сопротивлением $30 \mathrm{M} \Omega$. При этом ВАХ, измеренная при контакте зонда с окисленной поверхностью (р. 3), имеет выпрямляющий (диодный) вид, типичный для барьера Шоттки с полупроводником $n$-типа. Отметим, что в широком диапазоне напряжений окисленная область является изолирующей относительно невозмущенной поверхности.

На рис. $1, d$ представлен спектр КРС, полученный в точке скопления продуктов взаимодействия зонда с поверхностью (р. 2). В спектре наблюдаются широкие полосы $D\left(\sim 1345 \mathrm{~cm}^{-1}\right), \quad G\left(\sim 1603 \mathrm{~cm}^{-1}\right)$ и $2 D\left(\sim 2692 \mathrm{~cm}^{-1}\right)[5]$. Такой вид спектра является типичным для оксида графена [9]. По сравнению со спектром КРС исходного неокисленного графенового слоя (он приведен на вставке к рис. $1, d$ ) для спектра GO характерно значительное уширение $G$-полосы и существенное увеличение интенсивности $D$-полосы. Известно, что отношение интегральных интенсивностей пиков $\left(I_{D} / I_{G}\right)$ является мерой степени беспорядка и обратно пропорционально среднему размеру $s p^{2}$-кластеров $[10,11]$. Увеличение этого параметра в спектре GO указывает на его бо́льшую дефектность и уменьшение размера $s p^{2}$-кластеров в нем по сравнению с неокисленным слоем. Кроме того, интенсивность $2 D$-полосы в GO

Письма в ЖТФ, 2018, том 44, вып. 9 
подавлена из-за снижения количества бездефектных атомов с $s p^{2}$ электронной структурой. В спектре КРС GO в области высоких частот кроме $2 D$-полосы наблюдается еще несколько полос $(\sim 2931$ и $\sim 3188 \mathrm{~cm}^{-1}$ ), которые связаны с особенностями его электронной структуры [9]. Таким образом, анализ спектра КРС позволяет сделать вывод о модификации поверхности графена, ведущей к образованию оксида графена.

Влажность оказывает сильное влияние на процесс окисления. Чем выше уровень влажности, тем при меньшем значении напряжения на зонде происходит окисление. Однако высокий уровень влажности $(\sim 60 \%)$ приводит к ухудшению локальности процесса. Окисление уже не происходит в области под зондом, а распространяется на области с адсорбировавшейся водой вокруг зонда, размер которых может достигать несколько микрометров.

После подтверждения формирования оксида графена при ЛАО были проведены исследования режимов окисления (напряжение на зонде и скорость сканирования) при относительной влажности 45\%. Наиболее эффективным был режим $-15 \mathrm{~V}$ и $1 \mu \mathrm{m} / \mathrm{s}$, так как в нем сочетаются умеренное напряжение на зонде, достаточная для быстрой обработки больших площадей скорость зонда и равномерное окисление поверхности. Отметим, что при увеличении скорости сканирования на $1 \mu \mathrm{m} / \mathrm{s}$ необходимо изменять напряжение на зонде на $-5 \mathrm{~V}$ (например, $2 \mu \mathrm{m} / \mathrm{s},-20 \mathrm{~V}$ и т.д.).

Данные о режимах окисления позволили перейти к экспериментам по получению минимального разрешения литографии. Для этого были использованы зонды с меньшим радиусом острия (NT-MDT: HA_FM/W2C $\sim 20-30 \mathrm{~nm})$. Был проведен эксперимент по получению графеновой наноленты, а также наносужения области графена как можно меньшей ширины. Недавно в работе [12] авторы продемонстрировали рекордное наносужение шириной $10 \mathrm{~nm}$, достигнутое на монослое графена, полученном методом механического отшелушивания графита и перенесенном на подложку $\mathrm{SiO}_{2}$.

Детектирование окисленных областей и зазора между ними с линейным размером в десятки нанометров, как правило, выполняется с помощью измерения силы трения зонда о поверхность, поскольку трение между зондом и оксидом графена больше трения между зондом и графеном [10]. На рис. 2 представлены карты распределения силы трения участка поверхности, на котором методом ЛАО формировались

Письма в ЖТФ, 2018, том 44, вып. 9 


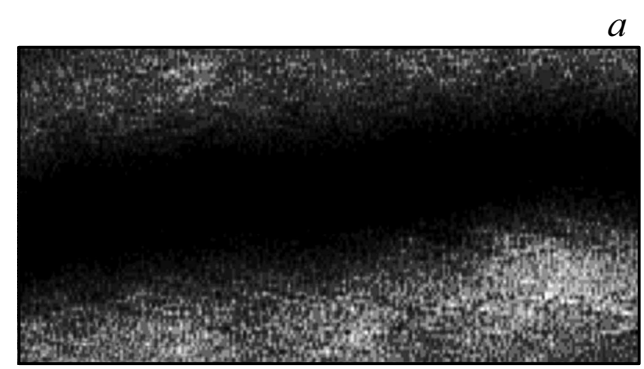

$20 \mathrm{~nm}$

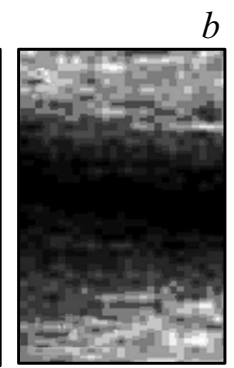

$10 \mathrm{~nm}$

Рис. 2. Графеновая нанолента (ширина $\sim 20 \mathrm{~nm}$ ) (a) и графеновое наносужение (ширина $\sim 10 \mathrm{~nm})(b)$ между двумя окисленными областями.

узкая неокисленная графеновая нанолента шириной $20 \mathrm{~nm}$ (рис. 2,a) и наносужение шириной $10 \mathrm{~nm}$ (рис. 2,b), что сопоставимо с лучшими результатами, полученными на отшелушенном графене. Светлые области на изображении соответствуют окисленному графену, темные неокисленному. В результате серии экспериментов были определены оптимальные параметры литографии, обеспечивающие наибольшее разрешение. Данная литография проводилась в контактном режиме при относительной влажности воздуха $\sim 45 \%$, напряжении $-6 \mathrm{~V}$, скорости зонда $0.2 \mu \mathrm{m} / \mathrm{s}$ и времени воздействия на точку $10 \mathrm{~ms}$.

Таким образом, в работе исследовано влияние параметров (электрического напряжения и скорости сканирования) на окисление монослоев графена. Определены параметры, обеспечивающие воспроизводимое формирование оксида графена. Получены экспериментальные данные о проводимости, потенциале, топографии и кристаллической структуре окисленных областей. Результаты работы позволяют говорить о локальном анодном окислении графена на $\mathrm{SiC}$ как о методе нанолитографии с разрешением $10 \mathrm{~nm}$, который может быть использован для создания устройств на основе тонких слоев графена.

Работа П.А. Алексеева и Б.Р. Бородина поддержана грантом Президента РФ МК-5852.2018.2. Работа С.П. Лебедева поддержана стипендией Президента РФ для молодых ученых и аспирантов (СП-3472.2016.4).

Письма в ЖТФ, 2018, том 44, вып. 9 


\section{Список литературы}

[1] Novoselov K.S., Geim A.K., Morozov S.V., Jiang D., Zhang Y., Dubonos S.V., Grigorieva I.V., Firsov A.A. // Science. 2004. V. 306. P. 666-669.

[2] Lin Y.-M., Jenkins K.A., Valdes-Garcia A., Small J.P., Farmer D.B., Avouris P. // Nano Lett. 2009. V. 9. P. 422-426.

[3] Han T.-H., Lee Y., Choi M.-R., Woo S.-H., Bae S.-H., Hong B.H., Ahn J.-H., Lee T.-W. // Nature Photon. 2012. V. 6. P. 105-110.

[4] Emtsev K.V., Bostwick A., Horn K., Jobst J., Kellogg G.L., Ley L., McChesney J.L., Ohta T., Reshanov S.A., Röhrl J., Rotenberg E., Schmid A.K., Waldmann D., Weber H.B., Seyller T. // Nature Mater. 2009. V. 8. P. 203-207.

[5] Давыдов В.Ю., Усачёв Д.Ю., Лебедев С.П., Смирнов А.Н., Левицкий В.С., Елисеев И.А., Алексеев П.А., Дунаевский М.С., Вилков О.Ю., Рыбкин А.Г., Лебедев А.А. // ФТП. 2017. Т. 51. В. 8. С. 1116-1124.

[6] Song H.S., Li S.L., Miyazaki H., Sato S., Hayashi K., Yamada A., Yokoyama N., Tsukagoshi K. // Sci. Rep. 2012. V. 2. P. 337.

[7] Masubuchi S., Ono M., Yoshida K., Hirakawa K., Machida T. // Appl. Phys. Lett. 2009. V. 94. P. 082107.

[8] Colangelo F., Piazza V., Coletti C., Roddaro S., Beltram F., Pingue P. // Nanotechnology. 2017. V. 28. P. 105709.

[9] Arul R., Oosterbeek R.N., Robertson J., Xu G., Jin J., Simpson M.C. // Carbon. 2016. V. 99. P. 423-431.

[10] Beams R., Cançado L.G., Novotny L. // J. Phys.: Condens. Matter. 2015. V. 27. P. 083002.

[11] Cançado L.G., Takai K., Enoki T., Endo M., Kim Y.A., Mizusaki H., Jorio A., Coelho L.N., Magalhães-Paniago R., Pimenta M.A. // Appl. Phys. Lett. 2006. V. 88. P. 163106.

[12] Arai M., Masubuchi S., Nose K., Mitsuda Y., Machida T. // Jpn. J. Appl. Phys. 2015. V. 54. P. 04DJ06. 